\title{
A INFLUÊNCIA DO ALINHAMENTO DO PARANAPANEMA NA CONFIGURAÇÃO DO RELEVO E REDE DE DRENAGEM NA BACIA DO RIBEIRÃO FAXINAL, ITAPETININGA - SP
}

\author{
Richard Vinícius Siqueira Ribeiro ${ }^{(a)}$, Emerson Martins Arruda ${ }^{(b)}$ \\ (a) Departamento de Geografia, Turismo e Humanidades/Universidade Federal de São Carlos - Campus Sorocaba, \\ richard_siqueira15@hotmail.com \\ (b) Departamento de Geografia, Turismo e Humanidades/Universidade Federal de São Carlos - Campus Sorocaba, \\ emersongeo@ufscar.br.
}

\section{Eixo: SISTEMAS GEOMORFOLÓGICOS: ESTRUTURA, DINÂMICA E PROCESSOS}

\begin{abstract}
Resumo
O trabalho desenvolveu a caracterização geomorfológica da bacia hidrográfica do Ribeirão Faxinal no município de Itapetininga, a fim de compreender as características do relevo e da rede hidrográfica na área de estudos. O método de sistemas ambientais e a classificação das ordens taxonômicas nortearam a análise dos resultados obtidos e sua integração. Mapeamentos temáticos foram realizados. A aplicação dos parâmetros morfométricos também contribuiu para o entendimento sobre a dinâmica morfoestrutural da região. A bacia hidrográfica como unidade espacial de análise integra os elementos presentes na paisagem, destacando o papel da rede de drenagem na evolução do relevo regional ao longo do Quaternário. Os resultados obtidos demonstram que há uma grande influência da tectônica regional, sobretudo na compartimentação do relevo da área e da configuração da rede de drenagem. Oscilações climáticas ao longo do Quaternário certamente atuaram na esculturação do relevo e na distribuição dos depósitos sedimentares na bacia em questão.
\end{abstract}

\section{Palavras chave: Geomorfologia, Quaternário, Bacia Hidrográfica, Morfometria, Itapetininga.}

\section{Introdução}

O objetivo da pesquisa foi a caracterização geomorfológica de uma bacia hidrográfica do Ribeirão Faxinal, região de Itapetininga (SP), a partir da influência dos condicionantes morfoestruturais sobre o relevo e a rede de drenagem, sobretudo o controle imposto pelo Alinhamento de Pararapanema nas feições regionais. A região carece de produções científicas relacionadas à ciência da geomorfologia, fato este que motivou a produção acadêmica, pois a mesma não só contribui para o ambiente acadêmico como para toda sociedade civil envolvida. Optou-se assim pelo mapeamento da área bem como a utilização de índices morfométricos. A análise morfométrica contribui de forma signifivativa no entendimento da dinâmica do relevo, otimizando o conhecimento sobre processos e formas pretéritas que condicionam o comportamento da rede de drenagem da bacia hidrográfica (Hackspacher, et. al. 2010). A área encontra-se na Depressão Periférica Paulista, na Zona do Rio Paranapanema, tendo seu relevo influenciado tanto pela história de denudação da bacia sedimentar ao longo do Terciário e Quaternário e também sendo influenciada por 


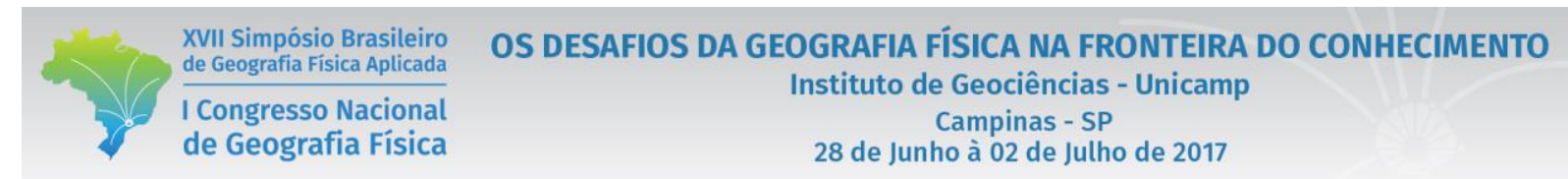

importantes lineamentos, resultados da tectônica regional mesozoica e possivelmente cenozoica. A área estudada se encontra entre os municípos de Itapetininga - SP e São Miguel Arcanjo - SP, na porção sudeste do estado de São Paulo, como demonstra o mapa de localização (Figura 1). Possui uma área de $82,37 \mathrm{~km}^{2}$ e perimetro de $51,77 \mathrm{~km}$. A área da bacia insere-se entre as longitudes $47^{\circ} 58^{\prime} 50^{\prime \prime} \mathrm{W} / 47^{\circ} 58^{\prime}$ 53 ” W e latitudes $23^{\circ} 47^{\prime} 36^{\prime \prime} \mathrm{S} / 23^{\circ} 39^{\prime} 39^{\prime \prime} \mathrm{S}$.

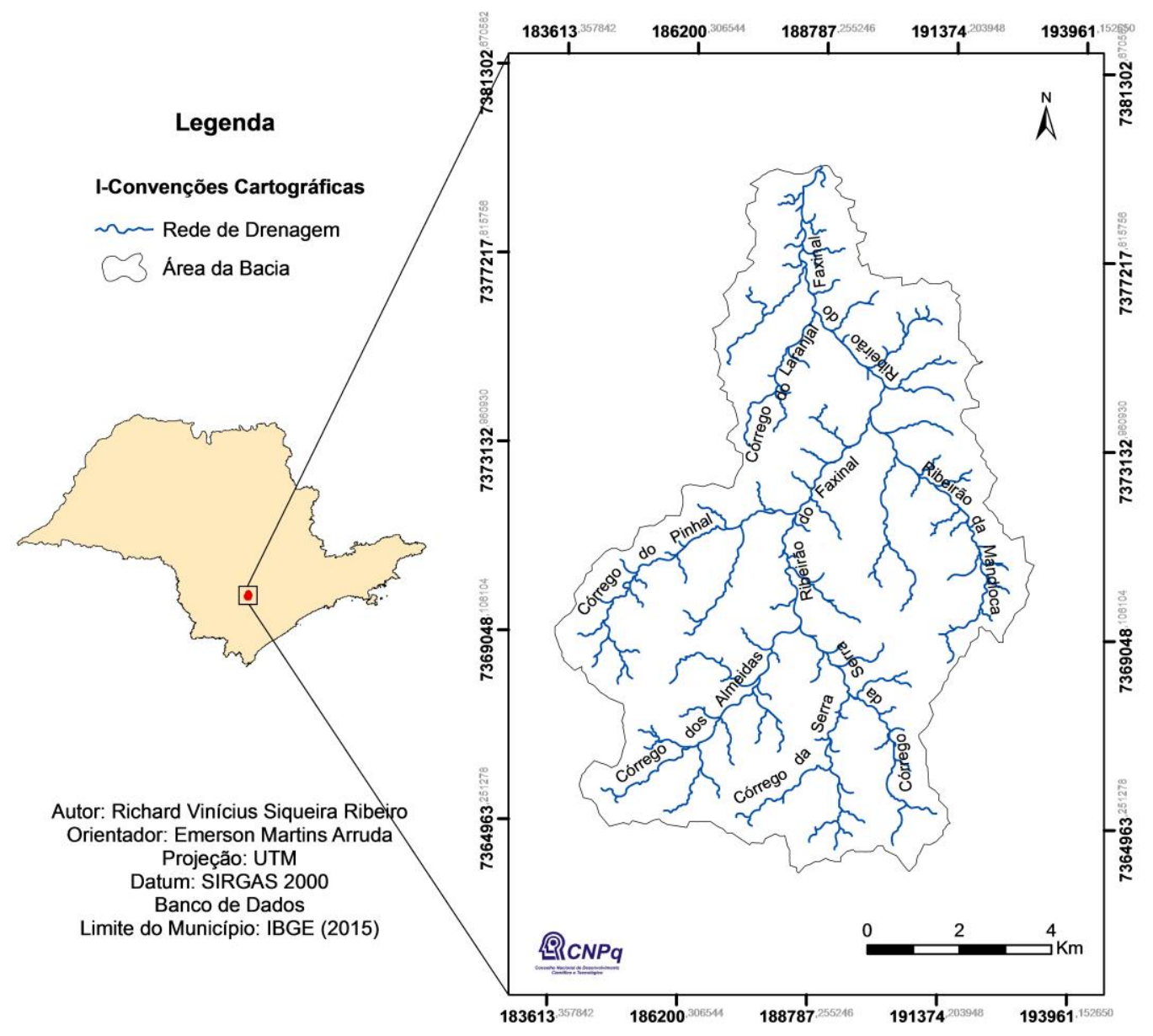

Figura 1 - Mapa de localização do Riberião Faxinal.

\section{Método e Metodologia}

O método escolhido foi a abordagem de sistemas ambientais de Christofolleti (1981) o qual contribuiu como aporte teórico necessário para o desenvolvimento da pesquisa. A abordagem sistêmica auxilia nos estudos da geomorfologia, principalmente nas questões de análise da paisagem e os processos de formação e na complexidade dos elementos naturais e como eles se interagem. A metodologia se iniciou com o levantamento da bibliografia específica sobre a geomorfologia da região da bacia analisada bem como 
sobre o tema abordado. Seguiu-se a proposta dos índices morfométricos como RDE (Hack, 1973) e Perfil Longitudinal adaptado por Etchebehere (2004). Segundo Etchbehere (et. al. 2006) a aplicação dos parâmetros morfométricos em sistemas fluviais proporcionam resultados favoráveis sobre deformações da crosta e mudanças na compartimentação do relevo e rede de drenagem, uma vez que os canais fluvias reagem a qualquer alteração do relevo, demonstrando assim alterações no nível de base condicinadas por condições climáticas passadas ou por eventos de cunho tectônico. Já a elaboração dos mapas temáticos auxiliou na interpretação do relevo da área. Foram elaborados os mapas de declividade, hipsométrico e ainda alguns modelos numéricos do terreno, a partir de software de geoprocessamento. Nessa etapa do trabalho foram identificadas as unidades de relevo que compôem a compartimentação da área. Para tal utitizou-se das ordens taxonômicas de Ross (1992). Já o mapa geomorfológico foi fundamentado nos trabalhos de Verstappen e Zuidam (1995), e na utilização de simbologias propostas por Tricart (1972). Os trabalhos de campo foram essenciais para comparar os dados obtidos em gabinte com o real, permitindo assim analisar os processos morfodinâmicos influenciam na evolução da paisagem.

\section{Resultados e Discussões}

Partindo da proposta das ordens taxonômicas, concluiu-se que a área da bacia hidrográfica tem três padrões de relevo e sendo assim optou-se em dividir a área em três setores: setor 1 , setor 2 e setor 3 . O setor 1 demonstrou padrões de relevo em morros, topos restritos e aguçados, com encosta com alto grau de declividade $(19 \%$ a $>30 \%)$ que favorecem a aceleração dos processos erosivos. Encontraram-se ravinamentos e cicatrizes provenientes de movimentos de massa, processos estes que acentuam a morfogênese das vertentes nessa área da bacia. Além dessas caracteristicas supracitadas, foram encontradas algumas formações de linhas de pedras (stone lines), que podem indicar a forte influência das pulsações climáticas ao longo do Quaternário na dinâmica evolutiva do relevo e na configuração do tipo e sistema de drenagem. No setor 2 constatou-se mudanças no padrão do relevo de morros para colinas, com presença de alguns vales bem dissecados, vertentes de topos levemente convexizados e baixas encostas concavas-retilíneas. Predominam encostas com média de declividade inferiores à 18\%. A superfície marcada pelas colinas desse setor parece constituir resultado da dissecação e recuo das encostas em um antigo pediplanos regional. Pequenos trechos de inflexão do canal do Ribeirão Faxinal refletem a influência do controle lito-estrutural na organização do arranjo da rede de drenagem e na compartimentação do relevo da bacia. No setor 3 ocorrem dois padrões de interflúvios, alguns mais alongados acompanhando a drenagem de direção à NW e outras áreas de interfluvios mais isolados, com topos mais restritos. Foram observados neste setor os mais amplos terraços e planicies fluviais, com declividades inferiores à 5\%. As rupturas topográficas ao longo do vale do Ribeirão Faxinal e o próprio nível de base regional, o rio Itapetininga, onde o ribeirão conflue, interferem de modo significativo nas 
características e espacialização do relevo da área. A partir da aplicação dos métodos morfométricos, os dados obtidos demonstram algumas importantes especificidades dessas características. O índice de RDE foi aplicado no curso principal da bacia hidrográfica a fim de demonstram possiveis influências neotectônicas e climáticas na evolução da paisagem. A elaboração do perfil longitudinal auxiliou na identificação de anomalias, sendo possivel identificar no perfil longitudinal alguns trechos submetidos a possível processo de soerguimento (Figura 2), setores acima da linha de melhor ajuste. O setor abaixo da referida linha indica um possivel rebaixamento do nivel de base regional, próximo ao rio Itapetininga.

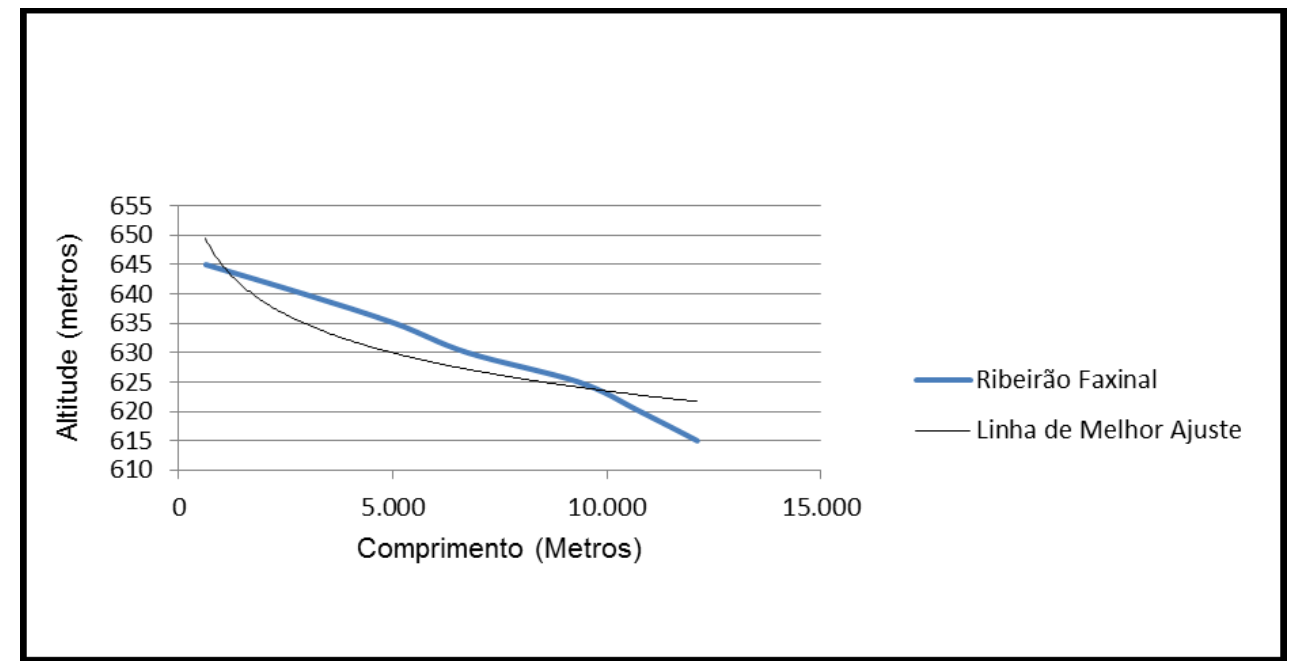

Figura 2: Perfil Longitudinal do Ribeirão Faxinal.

Apesar de a área apresentar certa homogeneidade litológica, associada ao Sub-Grupo Itararé, a mesma sofre influências de trends de lineamentos secundários, estruturas relacionadas a movimentação transcorrente do Alinhamento Alto-Estrutural do Paranapanema. Segundo Fúlfaro (1974), o alinhamento estrutural orientado de ESW para WNW influenciou de forma significativa a evolução do relevo regional da Bacia Sedimentar do Paraná, desde o Carbonífero ao fím do período Mesozóico. Como a movimentação do alinhamento é transcorrente, os blocos ao entorno do alinhamento alto-estrutural também sofrem influências dos processos tectônicos, ou seja, os indícios de soerguimento do canal fluvial do Ribeirão Faxinal e outros possíveis soerguimentos dispostos na área de estudo também podem ter relação direta com a movimentação transcorrente do alinhamento do Paranapanema, uma vez que o alinhamento gerou as atividades tectônicas para tal processo. Essa descontinuidade influenciou no processo de dissecação dos vales e as anomalias presentes no canal fluvial. O relevo da bacia também demonstrou indícios da influência tectônica do Alinhamento do Paranapanema, com a presença de encostas assimétricas, o que demostra que a há um grande controle lito-estrutural agindo sobre as formas do relevo. A disposição dos interflúvios, o posicionamento das rampas de colúvio e outros elementos da 
paisagem levantam a hipótese de possíveis soerguimentos provenientes da movimentação transcorrente da estrutura tectônica regional. Outros parâmetros estão sendo analisados para corroborar tais hipóteses.

\section{Considerações Finais}

Os resultados demonstram a influência de estruturas regionais na evolução e compartimentação geomorfológica da região de Itapetininga. Conclui-se que a área de estudos é diretamente influenciada pelos aspectos mosfoestruturais, tanto o relevo quanto a rede de drenagem, na escala da bacia por lineamentos secundários oriundos dos movimentos transcorrentes do alinhamento do Paranapanema. Constata-se que os resultados obtidos confirmam que há atividades tectônicas pretéritas e possivelmente recentes, características que aliadas à ação climática e à história de erosão, marcam a evolução da paisagem na área em questão. Os resultados obtidos por meio da aplicação dos parâmetros morfométricos demonstram a importância da utilização das técnicas específicas para o estudo do relevo e da rede de drenagem. Estudos geomorfológicos complementares serão realizados na bacia do Ribeirão Faxinal.

\section{Agradecimentos}

Ao Conselho Nacional de Desenvolvimento Científico e Tecnológico (CNPq) pela ajuda financeira e ao grupo de estudos do Quaternário da UFSCar, campus Sorocaba.

\section{Bibliografia}

CHRISTOFOLETTI, Antonio. Geomorfologia Fluvial. São Paulo: Edgard Blucher, 1981

ETCHEBEHERE, M. L.; SAAD, A. R.; FULFARO, V. J. e PERINOTTO, J.A.J .Aplicação do índice "Relação Declividade-Extensão - RDE" na bacia do Rio do Peixe (SP) para deteç̧ão de deformações neotectônicas. Geol. USP, Sér. cient. [online]. 2004, vol.4, n.2, pp. 43-56.

ETCHEBEHERE, M. L.; SAAD, A. R; SANTONI, G; CASADO, F.C; FULFARO, V. J. Deteç̧ão de prováveis deformações neotectônicas no vale do Rio do Peixe, região ocidental paulista, mediante aplicações de índices RDE (Relação Declividade-Extensão) em segmentos de drenagem. São Paulo, UNESP, geociências, v.25, n.3, p. 271-287, 2006.

FÚLFARO, J.V. Tectônica do alinhamento estrutural do Paranapanema. Boletim IG, USP, V.5 : 129-138, 1974.

GODOY, A. M, HACKSPACHER, P. C., OLIVEIRA, M. A. F. ARAÚJO, L. M. B. Evolução geológica dos Batólitos Granitóides Neoproterozóicos do sudeste do estado de São Paulo. São Paulo, Geociências, V. 29, n. 2, p. 171-185, 2010. 


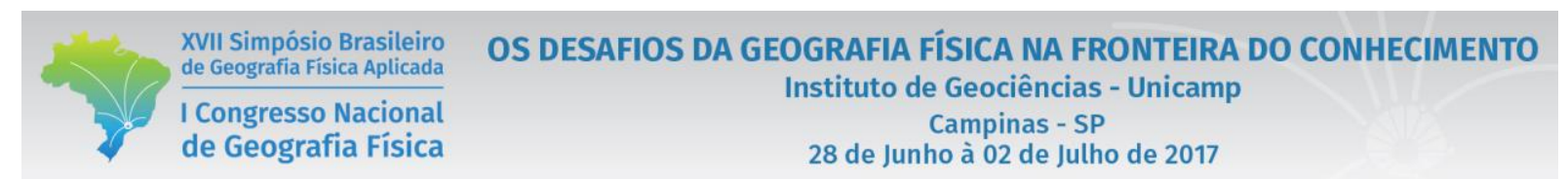

HACK, J.T. Stream-profile analysis and stream-gradient index. U.S. Geol. Survey, Jour. Research, v. 1, n. 4, p.421-429, 1973.

ROSS, J.L.S. Relevo Brasileiro: uma nova proposta de classificação. Revista do Departamento de Geografia, FFLCH/USP. São Paulo, 1985

TRICART, J - Principes et méthodes de la Géomorphologie. Masson et Cie., Éditeurs, Paris, 1965, 496 p.

VERSTAPEEN, H.T.; ZUIDAM, R.A. (ITC) - System of Geomorphological Servey. Manuel ITC, Text Book. Vol 7, Cap. 7, 1975. 